\title{
Self-Healing: A Concept for Musculoskeletal Body Pain Management - Scientific Evidence and Mode of Action
}

Joyce McSwan, ',* Jeffrey Gudin, ${ }^{2, *}$ Xue-Jun Song, ${ }^{3}$ Perola Grinberg Plapler, ${ }^{4}$ Neil John Betteridge, ${ }^{5}$ Hayet Kechemir, ${ }^{6}$ Iva Igracki-Turudic, ${ }^{7}$ Gisele Pickering ${ }^{8}$

'GCPHN Persistent Pain Program, PainWISE, Gold Coast, QLD, Australia; ${ }^{2}$ Department of Anesthesiology, University of Miami, Miller School of Medicine, Miami, FL, USA; ${ }^{3}$ SUSTech Center of Pain Medicine, School of Medicine, Southern University of Science and

Technology, Shenzhen, Guangdong, People's Republic of China; ${ }^{4}$ Division of Physical Medicine, Institute of Orthopedics and Traumatology, Hospital das Clínicas, Faculty of Medicine, University of São Paulo, São Paulo, Brazil; ${ }^{5}$ Neil Betteridge Associates Ltd, London, UK; ${ }^{6}$ Consumer Healthcare Medical Affairs Department, Sanofi CHC, Paris, France; ${ }^{7}$ Consumer Healthcare Medical Affairs Department, Sanofi CHC, Frankfurt Germany; ${ }^{8}$ Clinical Investigation Center CIC Inserm 1405, University Hospital Clermont-Ferrand,

Clermont-Ferrand, France

*These authors contributed equally to this work

\section{Video Abstract}

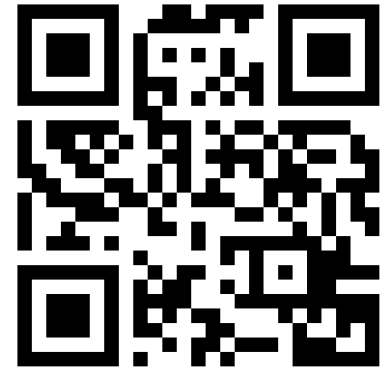

Point your SmartPhone at the code above. If you have a $Q R$ code reader the video abstract will appear. Or use: https://youtu.be/vz5fNChKbb4.

Correspondence: Gisele Pickering

Clinical Investigation Center CIC Inserm I405, University Hospital Clermont-Ferrand, rue Montalembert, CHU G Montpied, ClermontFerrand, 63000, France

$\mathrm{Tel}+33473178416$

Fax +33473178412

Email gisele.pickering@uca.fr

\begin{abstract}
Traditionally, musculoskeletal pain management has focused on the use of conventional treatments to relieve pain. However, multi-modal integrative medicine including alternative/complementary treatments is becoming more widely used and integrated into treatment guidelines around the world. The uptake of this approach varies according to country, with generally a higher uptake in developed countries and in females aged more than 40 years. Integral to the concept described here, is that the body has an innate ability to selfheal, which can be optimized by the use of integrative medical strategies. Stress triggers for acute or recurring musculoskeletal pain are diverse and can range from physical to psychological. The mechanism by which the body responds to triggers and initiates the self-healing processes is complex, but five body networks or processes are thought to be integral: the nervous system, microcirculation/vasodilation, immune modulation, muscular relaxation/ contraction and psychological balance. Multi-modal integrative medicine approaches include nutritional/dietary modification, postural/muscular training exercises, and cognitive behavioral mind/body techniques. This article will review the self-healing concept and provide plausible scientific evidence where available.
\end{abstract}

Keywords: innate, complementary, intrinsic ability, multi-modal, acute, equilibrium

\section{Introduction}

Pain influences quality of life and can be responsible for impairing autonomy, decreasing independence, and decreasing functional capacity. ${ }^{1}$ The definition of pain has recently been re-defined by the International Association for the Study of Pain (IASP) to "An unpleasant sensory and emotional experience associated with, or resembling that associated with, actual or potential tissue damage" (IASP 2020), ${ }^{2}$ and the definition of chronic pain was re-defined by the World Health Organization (WHO) in 2018 to "when pain has persisted for more than 3 months and is associated with significant emotional distress and/or functional disability, and the pain is not better accounted for by another condition" (WHO CD-11, 2018). ${ }^{3}$

Musculoskeletal pain affects the bones, muscles, ligaments, tendons, fascia and nerves. It can be acute (having a rapid onset with severe symptoms), and become recurrent with age, or can be chronic (long-lasting). Musculoskeletal pain accounts for $14 \%$ of all years lost to disability world-wide ${ }^{4}$ and includes localized pain such as low back, knee, shoulder, myofascial pain syndrome, and more widespread pain such as seen in fibromyalgia. The cause of musculoskeletal pain is not always clear, ${ }^{5}$ but known triggers include obesity, ${ }^{6-8}$ trauma and injury, ${ }^{9,10}$ overuse, ${ }^{11}$ 
aging, ${ }^{12}$ inflammation, ${ }^{13}$ and mental health disorders. ${ }^{14}$ In some cases, musculoskeletal pain is exacerbated by physiological hypersensitivity known as centralization, an increase in the excitability and synaptic efficacy of neurons in nociceptive pathways, often independent of inflammation. $^{15}$

Traditionally, musculoskeletal pain management has focused on the use of conventional treatments such as rehabilitation, non-steroidal anti-inflammatory drugs (NSAIDs), occasionally surgery, and even opioids to relieve pain. However, integrative medicine, which incorporates complementary and alternative medicine such as acupuncture, exercise, natural remedies and medical devices are becoming more widely used and integrated into guidelines around the world, ${ }^{16}$ including as first-line treatment (Table 1).

The American Board of Integrative Holistic Medicine (ABIHM) describes integrative medicine as focusing on the whole person, and making use of all appropriate therapeutic approaches to promote optimal health and healing. In light of the potential adverse effects associated with most pharmacotherapies, whole person healing is an age old philosophy more frequently being revisited. ${ }^{17}$

The use of integrative medicine therapies can potentially enable a self-managed approach. However, although patients with high health literacy are likely to be able to self-manage their musculoskeletal pain, patients with low health literacy, may seek care from healthcare professionals (HCPs). This indicates a need for both HCPs and patients to be educated on the self-healing concept. ${ }^{18}$

Whole person self-healing is a centuries old philosophy that has been refined using up-to-date research, to form the self-healing concept. For individuals with acute or recurrent musculoskeletal pain, body networks integral to the self-healing process, optimized by multimodal therapies, can help restore the whole person to equilibrium. This article will review each aspect of the self-healing concept and provide plausible scientific evidence where available.

\section{Musculoskeletal Pain Triggers}

Musculoskeletal pain can be localized or more widespread, such as in conditions like fibromyalgia, or can be due to myofascial pain syndrome (an independent cause of chronic pain that compounds the pain of other conditions). The causes of musculoskeletal pain can vary. Muscle tissue can become damaged in many ways including by the wear of daily activities, localized trauma, repetitive movement, postural strain, mental stress, and older age.
Many patients with musculoskeletal pain do not have a systemic disease or medical condition underlying the musculoskeletal pain experienced, and the cellular and molecular mechanisms are unclear. The sensation of musculoskeletal pain is mostly due to deep-tissue damage or strain, probably through activation of the polymodal muscular nociceptors. The intensity and duration of pain can determine the intensity of generalized muscle hyperalgesia and the potential transition from acute to chronic pain. $^{19-21}$

\section{Posture}

Body posture refers to body position and the alignment of body parts in relationship to the environment and is influenced by each joint. ${ }^{22}$ Posture is maintained by tonic muscle contractions acting against gravity and stabilizing the positions of body segments. The links between posture and pain are highly complex and controversial, but studies have shown that some habit forming posture, as reported in postural awareness questionnaires, may lead to chronic pain or further deterioration. ${ }^{22,23}$ Additionally, a sedentary lifestyle can be associated with a higher risk of musculoskeletal pain ${ }^{24}$ possibly due to muscle atrophy, caused by suppression of muscle protein synthesis as well as fiber denervation, neuromuscular junction damage, and upregulation of protein breakdown which can affect glucose homeostasis. $^{25}$

\section{Older Age}

Aging is associated with a loss of muscle mass, strength, and function that may result in sarcopenia, characterized by changes in muscle fiber size and type, motor nerve unit alterations and fatty infiltration of muscle. ${ }^{26}$ In addition bone strength, cartilage resilience, ligament elasticity and muscular strength reduce with age and fat redistribution increases with age, all of which diminish normal functioning of tissue. ${ }^{27}$ Studies predict that as the average age of individuals increases globally, musculoskeletal pain will become more widespread. ${ }^{12}$

\section{Intense Physical Activity}

Intensive work- and sport-related physical activity, can cause physical stress on muscle (peak mechanical loading) and along with sustained and/or repetitive movements, can present stress triggers for the development of tissue damage and musculoskeletal pain. ${ }^{11}$ 
Table I International Guideline Recommendations for Acute Low Back Pain

\begin{tabular}{|c|c|c|c|}
\hline Country & Guideline & $\begin{array}{c}\text { Year } \\
\text { Published }\end{array}$ & Disease Management Option in Guideline \\
\hline Australia & $\begin{array}{l}\text { eTG complete by Therapeutic Guidelines } \\
\text { Pain and analgesia: non-specific acute low back pain }{ }^{118} \\
\text { NSW Agency for Clinical Innovations Clinical Model of } \\
\text { Care } \\
\text { Management of people with low back pain: model of } \\
\text { care }{ }^{119}\end{array}$ & 2017 & $\begin{array}{l}\text { Ist line: Non-Pharmacological treatment, Massage and } \\
\text { thermotherapy } \\
\text { 2nd line: NSAIDs } \\
\text { 3rd line: Paracetamol } \\
\text { 4th line: Further investigation and follow-up } \\
\text { Ist line: Assessment, risk stratification, and patient } \\
\text { education } \\
\text { 2nd line: Active physical therapy and simple analgesic } \\
\text { medications } \\
\text { 3rd line: Complex medications, CBT } \\
\text { 4th line: Review, imaging and referral }\end{array}$ \\
\hline \multirow[t]{2}{*}{ Brazil } & $\begin{array}{l}\text { Brazilian Medical Association and Federal Council of } \\
\text { Medicine Project Guidelines (Projeto Diretrizes } \\
\text { Associação Médica Brasileira e Conselho Federal de } \\
\text { Medicina) } \\
\text { Diagnosis and treatment of low back and sciatica pain } \\
\text { (Diagnóstico e tratamento das lombalgias e } \\
\text { lombociatalgias) }\end{array}$ & 2001 & $\begin{array}{l}\text { Ist line: Rest, physical therapy, acetaminophen, dipyrone } \\
\text { 2nd line: NSAIDs } \\
\text { 3rd line: Corticosteroids } \\
\text { 4th line: Carisoprodol, cyclobenzaprine } \\
\text { 5th line: Trigger point inactivation } \\
\text { 6th line: Surgical treatments }\end{array}$ \\
\hline & $\begin{array}{l}\text { Brazilian Association of Physical Medicine and } \\
\text { Rehabilitation (Associação Brasileira de Medicina Física e } \\
\text { Reabilitação) } \\
\text { Chronic nonspecific low back pain: rehabilitation } \\
\text { (Lombalgia inespecífica crônica: reabilitação) }^{121}\end{array}$ & 2013 & $\begin{array}{l}\text { Ist line: Pharmacological (acetaminophen, NSAIDs, } \\
\text { opiates, anti-depressants) and non-pharmacological } \\
\text { (exercise, ultrasound, thermal water, shortwave } \\
\text { diathermy) } \\
\text { 2nd line: muscle relaxants }\end{array}$ \\
\hline \multirow[t]{2}{*}{ France } & $\begin{array}{l}\text { High Authority of Health Recommendation of Good } \\
\text { Practice (Haute Autorité de Santé Recommandation de } \\
\text { Bonne Pratique) } \\
\text { Management of the patient with common low back pain } \\
\text { (Prise en charge du patient présentant une lombalgie } \\
\text { commune) }{ }^{122}\end{array}$ & 2019 & $\begin{array}{l}\text { Ist line: Patient Information, self-management } \\
\text { 2nd line: Physical activity, paracetamol, NSAIDs } \\
\text { 3rd line: Multidisciplinary approach } \\
\text { 4th line: Biopsychosocial }\end{array}$ \\
\hline & $\begin{array}{l}\text { French Society of Rheumatology (Société Française de } \\
\text { Rhumatologie) } \\
\text { How is low back pain or common low back pain treated? } \\
\text { (Comment se traite une lombalgie ou une } \\
\text { lomboradiculalgie commune?) }{ }^{123}\end{array}$ & 2019 & $\begin{array}{l}\text { Ist line: Reassurance } \\
\text { 2nd line: Pharmacological and non-pharmacological pain } \\
\text { treatment } \\
\text { 3rd line: Physical activity and psychosocial therapy }\end{array}$ \\
\hline \multirow[t]{2}{*}{ Germany } & $\begin{array}{l}\text { AWMF German Disease Management Guideline } \\
\text { Non-specific low-back pain }{ }^{124}\end{array}$ & 2017 & $\begin{array}{l}\text { Ist line: Physical activity and educative measures } \\
\text { 2nd line: Diclofenac, ibuprofen, naproxen } \\
\text { 3rd line: Celecoxib, etoricoxib, metamizole } \\
\text { 4th line: Heat, NSAIDs, multimodal treatment programs }\end{array}$ \\
\hline & $\begin{array}{l}\text { National German Guideline (S2k-Leitlinie) } \\
\text { Specific low back pain (Spezifischer kreuzschmerz) }\end{array}$ & 2018 & $\begin{array}{l}\text { Ist line: facet joint blocks, NSAIDs } \\
\text { 2nd line: Surgery }\end{array}$ \\
\hline UK & $\begin{array}{l}\text { NICE Guideline (NG59) } \\
\text { Low back pain and sciatica in over } 16 \text { s: assessment and } \\
\text { management }\end{array}$ & 2016 & $\begin{array}{l}\text { Risk stratification followed by activity promotion and self- } \\
\text { management. } \\
\text { Patients encouraged to remain at work } \\
\text { NSAIDs or weak opioid with/without paracetamol }\end{array}$ \\
\hline
\end{tabular}

(Continued) 
Table I (Continued).

\begin{tabular}{|c|c|c|c|}
\hline Country & Guideline & $\begin{array}{c}\text { Year } \\
\text { Published }\end{array}$ & Disease Management Option in Guideline \\
\hline \multirow[t]{3}{*}{ USA } & $\begin{array}{l}\text { Agency for Healthcare Research and Quality Effective } \\
\text { Healthcare Program } \\
\text { Noninvasive treatments for low back pain: current state of } \\
\text { the evidence }\end{array}$ & 2016 & $\begin{array}{l}\text { Ist line: Non-pharmacologic treatment (exercise, heat, } \\
\text { massage, acupuncture, manipulation). } \\
\text { 2nd line: NSAIDs or skeletal muscle relaxants } \\
\text { 3rd line: Combination therapy/low evidence for mind- } \\
\text { body interventions including yoga, tai chi and mindfulness }\end{array}$ \\
\hline & $\begin{array}{l}\text { VA/DoD Clinical Practice Guideline } \\
\text { Diagnosis and treatment of low back pain }{ }^{128}\end{array}$ & 2017 & $\begin{array}{l}\text { Ist line: Education and self-care } \\
\text { 2nd line: Non-pharmacological therapies } \\
\text { 3rd line: Prescription NSAIDs or non-benzodiazepine } \\
\text { skeletal muscle relaxants } \\
\text { 4th line: Intensive interdisciplinary rehabilitation }\end{array}$ \\
\hline & $\begin{array}{l}\text { Clinical Practice Guideline from the American College of } \\
\text { Physicians } \\
\text { Noninvasive treatments for acute, subacute, and chronic } \\
\text { low back pain }{ }^{38}\end{array}$ & 2017 & $\begin{array}{l}\text { Ist line: Non-pharmacological treatments (heat, massage, } \\
\text { acupuncture, spinal manipulation, yoga, relaxation, } \\
\text { cognitive behavioral therapy or mindfulness-based stress } \\
\text { reduction). } \\
\text { 2nd line: NSAIDs } \\
\text { 3rd line: Tramadol or duloxetine } \\
\text { 4th line: Opioids }\end{array}$ \\
\hline
\end{tabular}

Abbreviations: AHRQ, Agency for Healthcare Research and Quality; AWMF, Association of the Scientific Medical Societies in Germany; CBT, cognitive behavioral therapy; DoD, Department of Defense; NICE, National Institute for Health and Care Excellence; NSAIDs, non-steroidal anti-inflammatory drugs; NSW, New South Wales; VA, Veterans' Affairs.

\section{Trauma and Injury}

Musculoskeletal pain caused by trauma and injury (vehicle accidents, sprains, falls, fractures, dislocations, and direct blows to the muscle) can be prolonged. A recent study has shown that after trauma/injury, at 4 months $11 \%$ of patients developed moderate-to-severe pain and $21 \%$ had symptoms immediately after injury that were prolonged. ${ }^{10}$

\section{Depression and Mental Health}

Pain and disability are linked to a range of psychosocial and physical factors. For example, depression can affect pain and disability. ${ }^{14}$ Furthermore, a link has been found between harassment (workplace bullying) and musculoskeletal pain. ${ }^{28}$ One hypothesis for the link between mental health and pain, is that raised anxiety may lead to increased muscular tension, which in turn may lead to increased pain. ${ }^{29}$ In the context of chronic pain, hippocampal connectivity to the posterior insula and anterior cingulate cortex (ACC) has been associated with negative attentional bias, increased sensitivity to unpleasant stimuli, and pain catastrophizing involving the insula, ACC and dorsolateral prefrontal cortex. ${ }^{30}$

\section{Obesity}

Traditionally, it has been argued that obesity is a trigger for musculoskeletal pain because of increased mechanical loading. However, conflicting studies have indicated that this may be a simplistic view. ${ }^{6-8}$ Adipose tissue is an endocrine organ secreting cytokines (adipokines) that contribute to inflammation and hormones, some of which may be associated with the musculoskeletal pain. ${ }^{31}$ A recent systematic review shows that increased body fat, not body weight per se, is likely to be associated with low back, knee, and foot pain. ${ }^{32}$

\section{Inflammation}

Persistent inflammation is a stress trigger that may contribute to all non-traumatic musculoskeletal pain, in particular ageing-related pathologies such as osteoporosis, osteoarthritis, and sarcopenia. ${ }^{13}$ The inflammatory response involves many proinflammatory cytokines and chemokines and the termination of this response is critical to prevent unwanted tissue damage. ${ }^{13}$ Oxidative stress can also lead to chronic inflammation. In patients with fibromyalgia, it has been shown that increased oxidative stress may play a role in the etiology and pathogenesis of musculoskeletal pain. ${ }^{33}$ 


\section{An Integrative Medicine Approach to Managing Pain}

An integrative medicine approach to manage pain incorporating complementary/alternative therapies (Table 1) has become more widespread in recent years and more accepted by both patients and HCPs although this differs widely by country and region. There are many reasons for the potential inclusion of complementary/alternative therapies in guidelines: conventional therapies do not always adequately address the needs of the growing number of patients living with chronic pain, and often treat the symptoms of the disease without effectively addressing the underlying causes. A reduced reliance on conventional analgesic medicines can help limit the adverse effects, including opioids, NSAIDs, antidepressants, anticonvulsants (anti-epileptics), and corticosteroids. ${ }^{34,35}$ In contrast, complementary/alternative therapies mostly have minimal side effects. ${ }^{35}$ Integrative medicine approaches also encompass psychosocial factors (interaction of social factors and an individual's behavior and mental health) and can help maintain both psychosocial and spiritual health through techniques such as mindfulness. Other activities such as yoga and physical exercise can help mental health and reduce depression which can likewise reduce pain. ${ }^{14,36}$

Integrative medicine approaches to the management of pain have been studied in a range of patient groups and settings. Petri et al discussed self-management of pain and integrative medicine programs as part of treatment plans for service personnel and concluded that they could be effectively incorporated. They did, however, add that further education, international collaboration, and research were necessary to increase use. ${ }^{37}$ Another study of American service personnel found that a change in mind-set towards integrative medicine approaches can bring benefits. For example, swapping the order of therapy, eg, to start with yoga, massage chiropractic care, or acupuncture, before moving to drugs and other traditional interventions, resulted in lower levels of pain. ${ }^{38}$ Integrative medicine approaches are also used in palliative/long-term care settings where such approaches have shown they can be used to help patients meet their spiritual needs (expectations for meaning, purpose, and value in life). ${ }^{39}$ A pilot project of quantitative and qualitative outcomes from complementary and integrative medicine healthcare in a long-term care facility suggested that integrative medicine approaches can be safely implemented and may provide pain relief and enhanced well-being for residents. ${ }^{40}$ In addition, the effect of integrative medicine on pain management in a tertiary care hospital setting has been shown for hospitalized patients, to have a significant impact on pain scores self-reported pain was reduced by $50 \%$ without increased risk of adverse effects. ${ }^{41}$

\section{Uptake of Complementaryl Alternative Medicine Across the World}

Numerous studies have evaluated the factors determining the use of complementary/alternative medicine between different populations and countries. A systematic review of 49 studies from 15 countries showed that adults were more frequent users of complementary/alternative medicine than children, with use higher in East Asian countries such as Japan, South Korea, and Malaysia. ${ }^{42}$ In a study from the USA, use was similar across regions, with the populations most likely to employ complementary/alternative medicine being Asian and Caucasian, college educated, women, and those aged 45 to 64 years. ${ }^{43}$ Other studies assessing the sociodemographic determinants of complementary/alternative medicine use in 21 European countries also found that use was more prevalent among those employed, with a higher education and middle-aged women, with the oldest and youngest age groups least likely to uptake this type of medicine. ${ }^{44,45}$ Further, the type of complementary/alternative medicine varied according to income level, with lower income associated with the use of mind-body therapies, and higher income associated with the use of traditional and alternative medicines or manual body-based therapies. ${ }^{45} \mathrm{In}$ Europe, complementary/alternative medicine use further varied by country, for example complementary/alternative medicine use is widespread in Germany and France, but the uptake is not as high in Nordic countries. ${ }^{44}$ Studies in the UK and Australia reported similar patient profiles, with complementary/alternative medicine use more common in women, those with a higher education and those $>40$ years, though users in Australia were more likely to have a chronic condition. ${ }^{46,47}$ In the UK, the choice of complementary/ alternative also varied according to geographical location and socioeconomic status. ${ }^{47}$ Conversely, in developing countries, complementary/alternative medicine uptake was less likely. For example, a study in Brazil found that the prevalence of complementary/alternative medicine use was $4.5 \%$. However, complementary/alternative medicine use was still more common in females, those aged $>40$ years, and those with a higher education. Type of complementary/ alternative medicine use varied according to 
socioeconomical status, with upper social classes commonly accessing acupuncture and homeopathy and lower social classes using medicinal plants and herbal remedies. ${ }^{48}$

\section{Self-Healing Concept}

Self-healing is described as an intrinsic ability that has developed throughout evolution, ${ }^{49}$ and is in line with the Greek ideal of whole person healing. Psychology plays an important role within the self-healing process and there are psychological aspects to pain even within the conventional IASP 2020 definition "An unpleasant sensory and emotional experience associated with, or resembling that associated with, actual or potential tissue damage". ${ }^{2}$

The self-healing concept is an integrated set of body practices applied in the prevention and rehabilitation of a wide range of organic, physical, and visual diseases. The application of these techniques stimulates and balances the organic, physical, psychological functions in a harmonious way, as it allows the development of a dialog between the body, the mind, the emotions, and the sensations. ${ }^{50}$ It has been shown that health promotion programs in stress management, fitness, nutrition, weight control, and selfmedication improve health conditions; however, the impact on self-healing among people with acute and chronic diseases has also been shown to be mixed. ${ }^{51}$

Self-healing in the context of acute and recurring musculoskeletal pain is the innate process of the body and mind, to promote body networks to return to equilibrium and relieve pain. This may be regulated and optimized by the use of multimodal integrative therapies and refers to a naturally occurring sequence of events, not only of the body but also of the mind. Equilibrium refers to the condition in which all acting influences are balanced or canceled by equal opposing forces, resulting in homeostasis. ${ }^{52}$ When a stress trigger occurs, homeostasis is, or is perceived to be, threatened. ${ }^{53,54}$ Stress triggers for acute or recurring musculoskeletal pain are diverse and can range from the physical (eg, obesity and weight gain $^{32}$ ) to the psychological (eg, depression ${ }^{14}$ ). The mechanism by which the body responds to triggers and initiates self-healing processes is complex, but five body networks are potentially thought to be involved: the nervous system, ${ }^{53-56}$ microcirculation (vasodilation/vasoconstriction), ${ }^{57-60}$ immune modulation, ${ }^{55,61}$ muscular relaxation/contraction, ${ }^{11,59,62,63}$ and psychological balance. $^{55,64-68}$ Multi-modal integrative medicine approaches use multiple body networks to act on the whole person and therefore potentially help optimize the self-healing process. Approaches include nutritional/dietary modification, postural/muscular training exercises, and cognitive behavioral mind/body techniques.

\section{Body Networks Associated with Self-Healing - Mode of Action}

The cause of musculoskeletal pain is not always clear and the response of the body to musculoskeletal pain triggers is complex. The body networks described above can be associated with the innate ability of the body and mind to promote mechanisms to return to equilibrium, in order to help relieve pain induced by various triggers (the selfhealing process) (Figure 1).

\section{Muscular Relaxation/Contraction}

Muscle consumes the most energy of all organs in the body, by forcing other body systems to regulate blood flow and provide delivery of energy. ${ }^{11}$ Muscle contraction via actomyosin fibers occurs in response to neuronal stimulation and an influx of calcium from extra and intracellular sources. ${ }^{63}$ Muscle contraction commonly associated with certain painful conditions restricts blood flow which suggests that muscle relaxation is associated with an increased supply of oxygen and nutrients to muscle. $^{59}$

\section{Microcirculation (Vasodilation/ Vasoconstriction)}

The ability to match muscle blood flow to metabolic demand shows good musculoskeletal health. The microvasculature takes part in metabolic homeostasis by supplying oxygen and nutrients to active muscle fibers and helps remove metabolism byproducts. ${ }^{59}$ An increase in microcirculation may promote healing and reduce pain. Sufficient microcirculation is therefore necessary after blunt injury, to maximize the number of functional contractile elements. ${ }^{58}$ The degradation of microcirculation is linked to the chronification of pain and can increase the risk of neck/shoulder and low back pain. ${ }^{57,60}$

\section{Immune System Activation/Suppression (Inflammatory Mediators of}

\section{Regeneration)}

Reestablishing blood flow and tissue regeneration is a necessary component of healing and ultimately of pain relief. Acute inflammation plays a critical role in almost all stages of regeneration of muscle and other elements following trauma. Early in regeneration, necrosis of 


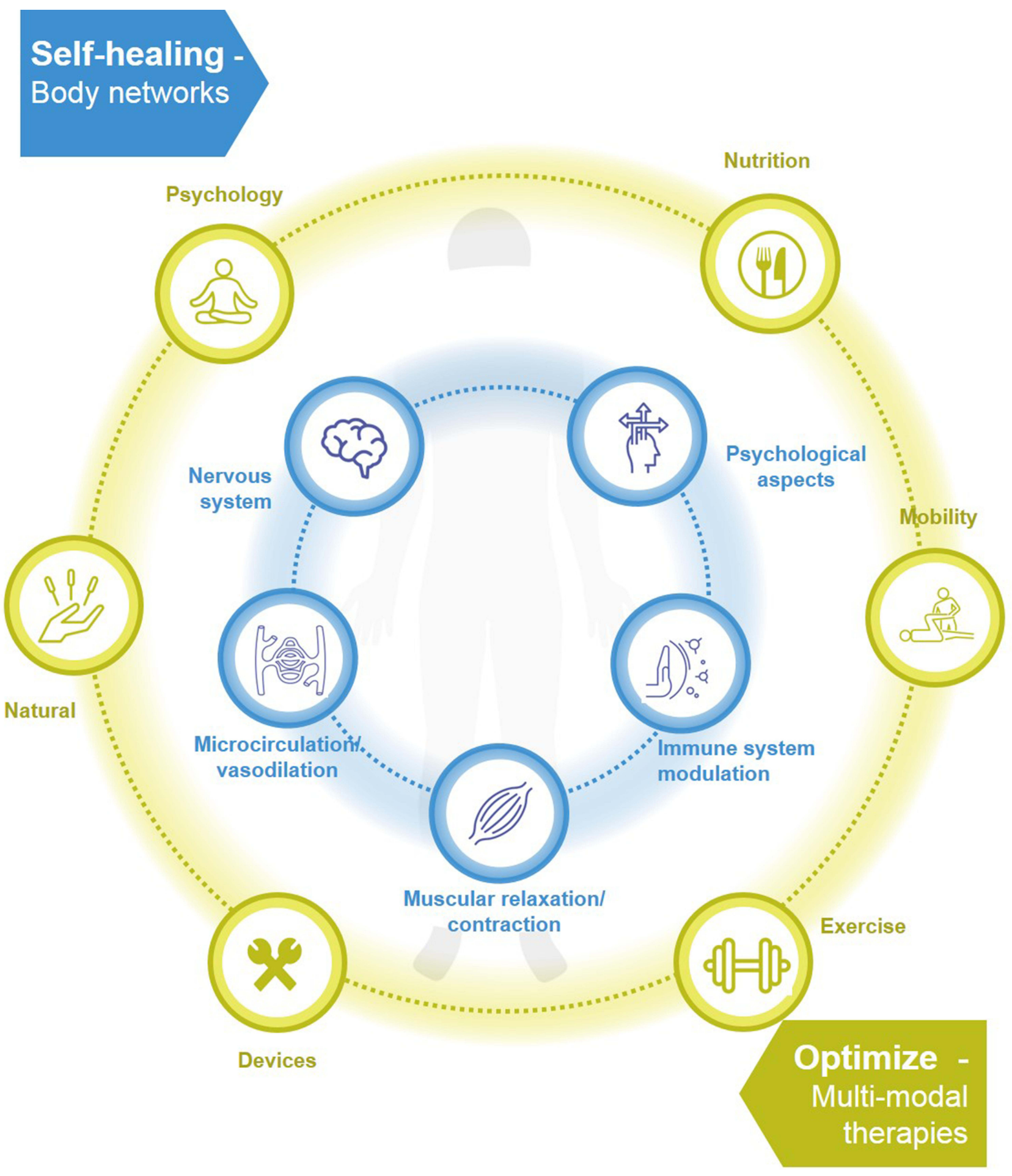

Figure I Self-healing concept: biological systems and mode of action.

injured cells is triggered in response to trauma and chemotactic factors and cell contents are released to the extracellular space. Many types of immune cells infiltrate including neutrophils and mast cells and help remove damaged myofibers at the site of injury as cytokines recruit more immune cells like macrophages. A cascade of cellular responses is triggered to regulate muscle stem cell activation, proliferation and differentiation and encourage muscle regeneration which can help avoid chronic inflammation and relieve pain. ${ }^{55}$ 


\section{Nervous System}

The autonomic nervous system bridges the central and the peripheral nervous systems and its activation is key to pain mechanisms. Sympathetic activation (and parasympathetic inhibition) by a stress trigger is associated with muscular contraction and pain. ${ }^{55}$ The sympathetic nervous system governs the "fight or flight" response, and is associated with an increase muscle tone, whereas the parasympathetic nervous system regulates the "rest and digest" response, and is associated with a decrease in muscle tone. ${ }^{53,54}$ To trigger the relaxation response, the parasympathetic nervous system blocks the stress response to slow heart rate processes, increases intestinal and gland activity, and in the gastrointestinal tract enables relaxation of sphincter muscles. ${ }^{53,54}$ The relaxation response may promote restoration and healing of the body by decreasing the physiological and psychological burden of chronic stress. ${ }^{56}$

\section{Psychological Aspects}

Psychological and cognitive strain, specifically in the case of catastrophizing or mental stress, may result in increased pain duration, muscle contraction, and can foster the transition from acute to chronic pain. Catastrophizing is a form of pain-specific psychological distress triggered by fear, which is characterized by a tendency to magnify the negative effect of pain. ${ }^{68}$ The presence of catastrophizing behavior predicts negative pain outcomes including chronic pain intensity, post-surgical pain intensity, disability, use of opioids, and persistent post-surgical pain. ${ }^{64}$ One study showed that catastrophizing was at least seven times more likely to predict the risk of subsequent chronic pain than any other factor among patients with acute back pain. ${ }^{69}$ Studies have also shown increased muscle activity not explained by physical load can be triggered by mental stress. ${ }^{55}$ Psychological factors play a significant role in the transition from acute to chronic pain; ${ }^{67}$ indeed, the psychological impact of a non-specific diagnosis can lead to "nonrecovery". For example, in a cohort of patients with arm, neck, and shoulder issues, $38 \%$ of patients with a specific diagnosis reported "nonrecovery" which increased to $49 \%$ after 6 months. ${ }^{66}$

\section{Integrative Medicine Within the Self-Healing Concept}

There are a multitude of integrative medicine approaches which can be applied to the self-healing concept (Figure 2). A common theme of all the therapies discussed is that they promote well-being and mental health and connect the body and the mind, an ideal central to the whole-person self-healing concept.

\section{Exercise}

Muscle strengthening through moderate exercise is linked to an increase in microcirculation associated with muscle contraction/relaxation. ${ }^{14,36}$ Intense physical activity can initiate musculoskeletal pain, but conversely, moderate physical activity can reduce it. Exercise and mechanical load on muscles causes hypertrophy (increased muscle mass induced by injury and hence repair and fusing of myofibers) and increases muscle strength. ${ }^{70}$ One approach to muscle strengthening is that of blood flow restriction training which takes advantage of hypertrophic repair and promotes neural and hypertrophic adaptations through a variety of endocrine, neural and metabolic mechanisms. ${ }^{71,72}$ A mind-body approach to exercise is that of Feldenkrais, internal awareness of movement and expanding the repertoire of movement has been shown in a randomized trial of 53 patients to significantly improve pain. ${ }^{73}$

\section{Mobility/Flexibility}

Muscle strengthening through physiotherapy is also linked to microcirculation and muscle contraction/relaxation. Physiotherapy provides a well-documented and important benefit in the management of musculoskeletal pain, although it requires sustained effort on the part of the patient. ${ }^{74}$ Stretch exercises to improve flexibility can help limit musculoskeletal pain by preventing repetitive strain and musculoskeletal injuries and improve mobility as shown in a single-blind 12-week research study. ${ }^{75}$ Regarding posture, every individual has a unique postural force/torque signature and muscle coordination strategies that induce differing degrees of mechanical wear of their musculoskeletal systems which may increase the risk of developing musculoskeletal disorders for some individuals. ${ }^{76}$ Spinal manipulation can improve musculoskeletal pain; it has been suggested that mechanical force initiates a cascade of neurophysiological responses from the peripheral and central nervous system. ${ }^{77}$

\section{Nutrition}

Dietary patterns have an integral role in musculoskeletal health. A systematic review indicated that a high protein, fat, and sugar intake were associated with increased pain intensity and a lower pain threshold. Conversely, plantbased diets might relieve chronic musculoskeletal pain. ${ }^{78}$ Furthermore, a high fat diet has also shown to be 


\section{Self-healing -}

\section{Body networks}

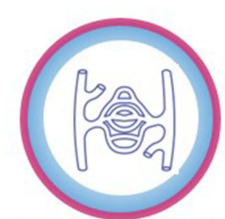

Microcirculation/ vasodilation

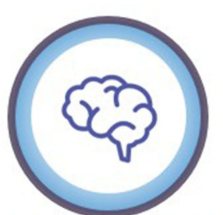

Nervous system

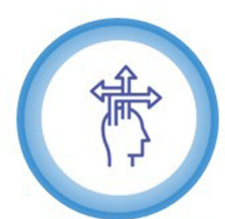

Psychology

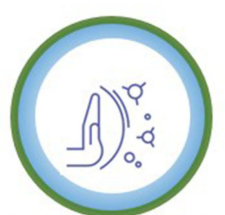

Immune system modulation

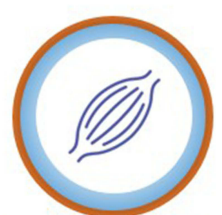

Muscular relaxation/ contraction

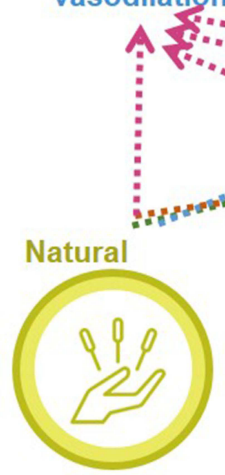

TCM

Melatonin Menthol Camphor Cannabidiol Salicylates
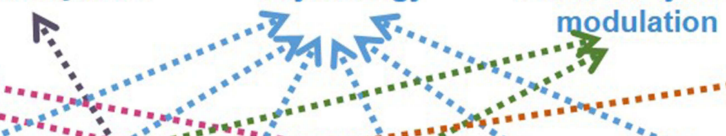

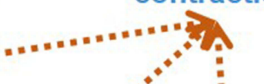

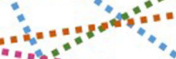

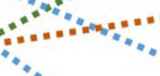<smiles>C1C[C@H]2C[C@H]1[C@H]1CC[C@@H]2C1</smiles>
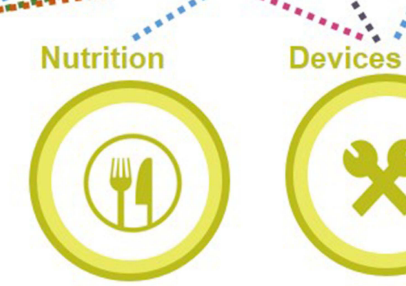

Diet

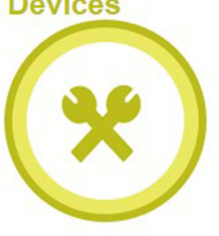

TENS

MET

B/D vitamins Multivitamins Fish oil

Pneumatic decompression Inversion traction Hot/cold

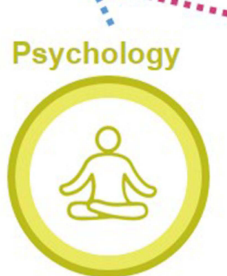

Mindfulness Visualisation Positive attitude Self-help books Meditation Hypnosis
(1)

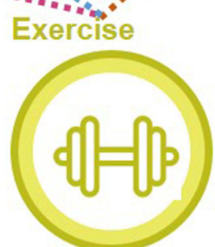

Moderate exercise

Posture

Feldenkrais

Qi Gong Tai chi Yoga

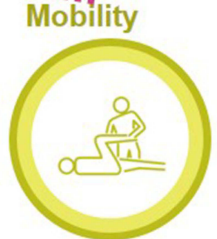

Physiotherapy Massage Sleeping position Posture Spinal manipulation Gravity free equipment Acupuncture

\section{Optimize - \\ Multi-modal \\ therapies}

Figure 2 Examples of integrative therapies and their links with the five body networks within the self-healing concept.

Abbreviations: MET, microcurrent electrical therapy; TCM, traditional Chinese medicine; TENS, transcutaneous electrical nerve stimulation.

associated with increased pain in animal models. ${ }^{79}$ An integrative review of 17 studies has also revealed that different nutritional interventions with specific diets, oils and/or fatty acids reduce musculoskeletal pain. In addition, nutritional interventions decreased the levels of several inflammatory markers including interleukin (IL)-6, IL-1 $\beta$, and tumor necrosis factor (TNF)- $\alpha .{ }^{80}$ Vitamins have also been shown to promote musculoskeletal health. ${ }^{81}$ The active form of vitamin D directly regulates musculoskeletal function, it is involved in cell proliferation, myogenesis, regulation of protein synthesis, differentiation, and mitochondrial metabolism through pathways including the mitogen-activated protein kinase pathway (s). ${ }^{81}$ Vitamin B is considered to have a role in bone health which is connected to musculoskeletal health. ${ }^{82}$

\section{Natural Therapies}

The bridging of Western and traditional Chinese medicine has been described as shifting compensatory homeostasis to overall human body homeostasis, in line with the self- 
healing idea, ${ }^{83}$ and among older Chinese adults, the use of traditional Chinese medicine has been shown to be effective, although there are some conflicting results. ${ }^{84,85}$ For example, menthol acts on vasculature directly in the vascular smooth muscle and endothelium and recent studies have shown that it causes an indirect vascular response via sensory fibers ${ }^{86}$ and menthol gel can acutely reduce pain intensity. ${ }^{87}$ Cold therapy can reduce edema in acute situations; vasoconstriction occurs both in response to reflex and local cooling of the skin; however, patients should be aware than cooling longer than 20 minutes can be harmful as a sudden switch to vasodilation can be triggered (hunting reaction). ${ }^{88}$ Conversely, heat therapy can be used to relieve pain and muscle cramps and increase blood flow and facilitate tissue healing. ${ }^{89}$ A randomized trial of 219 patients in 2003 showed low continuous heat wrap therapies to be effective for the treatment of acute, nonspecific low back pain, ${ }^{90}$ a result consistently confirmed in smaller more recent trials. ${ }^{91,92}$

\section{Devices and Techniques}

More and more devices are coming onto the market, for example portable transcutaneous electrical nerve stimulation (TENS) machines. ${ }^{93}$ TENS provides localized strong yet comfortable muscle contractions to ease musculoskeletal pain. ${ }^{93}$ Microcurrent Electrical Therapy (MET) is another portable system for patients, activating central pain modulatory mechanisms using resonant frequencies. Cells communicate throughout the body via the extracellular fluid and the circulatory system via cell-surface receptors. ${ }^{94}$ Acupuncture is effective for a number of chronic pain conditions as reported in a meta-analysis showing effects of acupuncture were persistent over time, and were not affected by placebo. ${ }^{95}$ Additionally, a systematic review has shown that acupuncture has an analgesic effect on the hypersensitivity of musculoskeletal pain caused by central sensitisation. ${ }^{96}$ Infra-red saunas have also been shown to affect the autonomic nervous system, placing the body in the parasympathetic (rest and digest) state and allowing it to heal. ${ }^{97}$ Additionally, infra-red can optimize the immune system as shown by the white blood cell profile and cortisol levels in athletes and non-athletes. ${ }^{98}$ Ultra low dose radiation is possibly helpful to enhance blood circulation and metabolism within the human body. ${ }^{99}$

\section{Psychology}

Yoga, mindfulness meditation, CBT and hypnosis are therapies that use psychological techniques to promote self-healing. Yoga combines physical exercises, meditation, and respiratory techniques that relieves stress whilst strengthening muscles. ${ }^{100}$ It also helps the body and mind to adapt to depression and anxiety and has a calming and relaxing effect on the individual. Studies have associated the practice of yoga with the relief of many chronic conditions such as low back pain. ${ }^{100}$ Mind-body interventions such as yoga may be integral to the integrative treatment of chronic pain conditions as they allow selfmanagement. ${ }^{100}$ Mindfulness is a mediation practice associated with changes in cognitive, sensorial experience and brain activity that has been shown to reduce levels of pain across a wide range of pain-related disorders including fibromyalgia. ${ }^{101-103}$ After a four-session meditation intervention, during a noxious heat stimulus, there was a mean $40 \%$ reduction in pain intensity and $57 \%$ reduction in pain unpleasantness ratings. ${ }^{103}$ In a small trial in Scotland of 34 patients, mindfulness meditation as a sole therapy for some involved a period of change which may help with painful and chronic conditions. ${ }^{104}$ Additionally, therapies such as cognitive behavioral therapy (CBT) are based on the concept that, "thoughts, feelings, physical sensations, and actions are interconnected". ${ }^{105}$ CBT has been shown to improve quality of life following 10 weeks of treatment. ${ }^{105}$ With regard to hypnosis, a study of healing in cancer patients could be applicable to musculoskeletal pain; the results from a recent study concluded

The intrinsic capacities of hypnotic phenomena, can be harnessed to effect perceptual and functional changes to offer symptom relief, re-establishment of systemic homeostasis, amelioration of cellular chemistry, and the acceleration of tissue healing. ${ }^{106}$

\section{Discussion}

The concept of self-healing aims to harness the innate ability of the body and mind to promote mechanisms to return to equilibrium, in order to help relieve pain induced by various triggers. Self-healing is potentially optimized by the use of multi-modal integrative medicine strategies which act on the whole person. The mode of action and science behind the process has been discussed throughout this article.

The uptake of integrative medicine is starting to increase around the world and is now present in many 
guidelines (Table 1), possibly as a reaction to the misuse of opioids in the US ${ }^{107}$ and Europe, ${ }^{108}$ and side effects of these and other conventional therapies. ${ }^{34,35}$ In addition, a systematic overview of current studies indicates that conventional pharmacological treatments have short-term benefits, whereas interventions such as exercise therapy and psychosocial interventions show moderate to strong evidence for reducing musculoskeletal pain in the longer term, although more clinical trials are needed. ${ }^{109}$ Whilst integrative medicine is becoming more widely used and incorporated in guidelines around the world, including as first-line treatment (Table 1), there is also a need for guidelines that focus more on self-managed approaches to acute or recurrent musculoskeletal pain.

Multi-modal integrative medicine as part of the selfhealing concept is compatible with a self-managed patientcentered approach. Patient self-management of care has been shown to be associated with lower healthcare use across primary and secondary care. ${ }^{110}$ Previous examples of successful patient self-management for pain are numerous; an Australian program guiding patients in pain management strategies showed significant improvements in patient self-reported pain and health distress. ${ }^{111}$ Additionally, it has been shown that optimized antidepressant therapy following self-managed pain resulted in less depression and some reduction in musculoskeletal pain severity ${ }^{12}$ Musculoskeletal pain was reduced following a community-targeted program ${ }^{111}$ and further, significant improvements in back pain have been demonstrated using exercise and self-management when compared with continued general practitioner management. ${ }^{113}$

There is a need for education about this self-healing multi-modal integrative medicine approach for both patients and HCPs; however, patient health literacy needs to be taken into account and approaches to education and self-management may need to be tailored to the patient. The Institute of Medicine reports that of the American adult population $50 \%$ may find acting on health information problematic. ${ }^{114}$ Furthermore, in a cross-sectional study, patients from Italy with low health literacy preferred a doctor-patient relationship whereas patients with high health literacy preferred a patient-centered approach. ${ }^{18}$ There are examples of education in the literature for acute or recurrent musculoskeletal pain although these would need to be tailored to the self-healing concept. Examples include a self-exercise education program for individuals with chronic low back pain which helps restore function and quality of life ${ }^{115}$ and a smartphone app, which could be a feasible way to implement both education and musculoskeletal care. ${ }^{116}$ There is also evidence in the form of a qualitative systematic review and metasynthesis that intermittent self-care support such as peer support and booster sessions might be of importance. ${ }^{117}$ Also of paramount importance, is that when HCPs are approached by patients with musculoskeletal pain, a correct diagnosis is made in order to avoid inappropriate treatment or delay in receiving the correct therapy.

Although there is literature evidence to link the mode of action of musculoskeletal pain with the body networks (immune system modulation, nervous system, muscular relaxation/contraction, microcirculation/vasodilation, and psychology), there are still many open-ended questions regarding integrative medicine as part of the whole person self-healing concept. As patient and HCP confidence in using multimodal integrative medicine therapies grow, more studies will be undertaken exploring integrative medicine options and analyzing how musculoskeletal pain is triggered and relieved. In the future, it will be necessary to undertake large-scale studies and develop guidelines for multimodal integrative medicine based on these results. In addition, promoting awareness and understanding of the self-healing concept will be needed in addition to undertaking economic studies so alternative approaches can be reimbursed. Limitations to the selfhealing approach include a lack of similar models for comparison and the need for more evidence to evaluate the effectiveness of integrative medicine approaches versus conventional therapy. Limitations to the analysis presented here include lack of large studies with adequate controls and that many studies are lacking in statistical power. Self-healing is hopefully a concept that will continue to evolve over time. The body has an innate ability to self-heal. The use of integrative medicine potentially helps to optimize the self-healing process and aids the body to return to its innate equilibrium, helping to relieve pain induced by various triggers. The self-healing concept is a multi-modal integrative medicine approach for adults with acute or recurrent musculoskeletal pain targeting whole person healing. Adequate guidelines and dissemination of education on the approach will all contribute towards the self-healing concept.

\section{Data Sharing Statement}

No datasets were generated or analyzed during the current study. 


\section{Acknowledgments}

XJ would like to thank Shenzhen Natural Science Foundation for funding his time and work (Basic Science 2019N394). Editorial support was provided by Ella Palmer, $\mathrm{PhD}$, CMPP of inScience Communications, Springer Healthcare Ltd, UK, and was funded by Sanofi.

\section{Author Contributions}

All authors made substantial contributions to conception and design, acquisition of data, or analysis and interpretation of data; took part in drafting the article or revising it critically for important intellectual content; agreed to submit to the current journal; gave final approval of the version to be published; and agreed to be accountable for all aspects of the work.

\section{Funding}

Medical writing support was funded by Sanofi.

\section{Disclosure}

JM has received funding from Arrotex, GSK, Mundipharma, Pfizer, Reckitt Benckiser, Sanofi, Sequiris and Viatris. JG has received consultancy fees from BDSI, Hisamitsu, Quest Diagnostics, Salix, Sanofi and Scilex Pharmaceuticals and is a shareholder in Virpax Pharmaceuticals. NJB has received consultancy fees from Amgen, Eli Lilly, EULAR, GAfPA, Grunenthal, Heart Valve Voice and Sanofi. PGP has received sponsorship for transportation and/or stay at congresses, participating in clinical and/or experimental studies subsidized by the industry, lecturing/speaking at sponsored events, participating in normative committees for scientific studies, receiving institutional support and preparing scientific texts in sponsored journals from Aché, AMGEM, Apsen, Biolab, EMS, Eurofarma, Hypera, Libbs, Lilly, Mylan, Sanofi, Zambon and Zodiac. HK and II-T are employees of Sanofi and may hold shares and/or stock options in the company. GP has received consultancy fees from Grunenthal, Mylan, MundiPharma and Sanofi.

\section{References}

1. Silveira MM, Potulski AP, Vidmar MF, Sachetti A, Wibelinger LM. Atividade Física e Qualidade de Vida em Idosos [Physical activity and quality of life in the elderly]. Saúde e Pesquisa. 2011;4(3). Portuguese.

2. Raja SN, Carr DB, Cohen M, et al. The revised international association for the study of pain definition of pain: concepts, challenges, and compromises. Pain. 2020;161(9):1976-1982. doi:10.1097/j.pain.00 00000000001939
3. Nicholas M, Vlaeyen J, Rief W, et al. The IASP classification of chronic pain for ICD-11: chronic primary pain. Pain. 2018;160:28-37. doi:10.1097/j.pain.0000000000001390

4. Institute for Health Metrics and Evaluation. Global burden of disease 2019; 2020. Available from: https://www.thelancet.com/ lancet/visualisations/gbd-compare. Accessed September, 2020.

5. Arendt-Nielsen L, Fernández-de-las-peñas C, Graven-Nielsen T. Basic aspects of musculoskeletal pain: from acute to chronic pain. J Man Manip Ther. 2011;19(4):186-193. doi:10.1179/1066981 $11 X 13129729551903$

6. Coenen P, Kingma I, Boot CR, Bongers PM, van Dieën JH. Cumulative mechanical low-back load at work is a determinant of low-back pain. Occup Environ Med. 2014;71(5):332-337. doi:10.1136/oemed-2013-101862

7. Hurwitz DE, Ryals AR, Block JA, Sharma L, Schnitzer TJ, Andriacchi TP. Knee pain and joint loading in subjects with osteoarthritis of the knee. J Orthop Res. 2000;18(4):572-579. doi:10.1002/jor.1100180409

8. Sullivan J, Burns J, Adams R, Pappas E, Crosbie J. Plantar heel pain and foot loading during normal walking. Gait Posture. 2015;41(2):688-693. doi:10.1016/j.gaitpost.2015.01.025

9. McCleskey EW, Gold MS. Ion channels of nociception. Annu Rev Physiol. 1999;61(1):835-856. doi:10.1146/annurev.physiol.61.1.835

10. Rosenbloom BN, Katz J, Chin KY, et al. Predicting pain outcomes after traumatic musculoskeletal injury. Pain. 2016;157 (8):1733-1743. doi:10.1097/j.pain.0000000000000580

11. Søgaard K, Sjøgaard G. Physical activity as cause and cure of muscular pain: evidence of underlying mechanisms. Exerc Sport Sci Rev. 2017;45(3):136-145. doi:10.1249/JES.0000000000000112

12. Vos T, Barber RM, Bell B, et al. Global, regional, and national incidence, prevalence, and years lived with disability for 301 acute and chronic diseases and injuries in 188 countries, 1990-2013: a systematic analysis for the Global Burden of Disease Study 2013. Lancet. 2015;386(9995):743-800.

13. Gallo J, Raska M, Kriegova E, Goodman SB. Inflammation and its resolution and the musculoskeletal system. J Orthop Translat. 2017;10:52-67. doi:10.1016/j.jot.2017.05.007

14. Marshall PWM, Schabrun S, Knox MF. Physical activity and the mediating effect of fear, depression, anxiety, and catastrophizing on pain related disability in people with chronic low back pain. PLoS One. 2017;12(7):e0180788. doi:10.1371/journal.pone.0180788

15. Woolf CJ. Central sensitization: implications for the diagnosis and treatment of pain. Pain. 2011;152(3 Suppl):S2-s15. doi:10.1016/j.pain.2010.09.030

16. World Health Organization. WHO global report on traditional and complementary medicine; 2019. Available from: https://www. who.int/traditional-complementary-integrative-medicine/ WhoGlobalReportOnTraditionalAndComplementaryMedicin e2019.pdf?ua=1. Accessed March, 2019.

17. Kleisiaris CF, Sfakianakis C, Papathanasiou IV. Health care practices in ancient Greece: the Hippocratic ideal. J Med Ethics Hist Med. 2014;7:6.

18. Camerini AL, Schulz PJ. Health literacy and patient empowerment: separating con-joined twins in the context of chronic low back pain. PLoS One. 2015;10(2):e0118032. doi:10.1371/journal. pone. 0118032

19. Fernández-de-las-peñas C, Ge HY, Arendt-Nielsen L, Cuadrado ML, Pareja JA. The local and referred pain from myofascial trigger points in the temporalis muscle contributes to pain profile in chronic tension-type headache. Clin J Pain. 2007;23(9):786792. doi:10.1097/AJP.0b013e318153496a

20. Herren-Gerber R, Weiss S, Arendt-Nielsen L, et al. Modulation of central hypersensitivity by nociceptive input in chronic pain after whiplash injury. Pain Med. 2004;5(4):366-376. doi:10.1111/ j.1526-4637.2004.04055.x 
21. Mense S. Nociception from skeletal muscle in relation to clinical muscle pain. Pain. 1993;54(3):241-289.

22. Cramer H, Mehling WE, Saha FJ, Dobos G, Lauche R. Postural awareness and its relation to pain: validation of an innovative instrument measuring awareness of body posture in patients with chronic pain. BMC Musculoskelet Disord. 2018;19(1):109. doi:10.1186/s12891-018-2031-9

23. Siebens HC. Musculoskeletal problems as comorbidities. Am J Phys Med Rehabil. 2007;86(1 Suppl):S69-78. doi:10.1097/ PHM.0b013e31802ba581

24. Kirsch Micheletti J, Bláfoss R, Sundstrup E, Bay H, Pastre CM, Andersen LL. Association between lifestyle and musculoskeletal pain: cross-sectional study among 10,000 adults from the general working population. BMC Musculoskelet Disord. 2019;20(1):609. doi:10.1186/s12891-019-3002-5

25. Narici M, De Vito G, Franchi M, et al. Impact of sedentarism due to the COVID-19 home confinement on neuromuscular, cardiovascular and metabolic health: physiological and pathophysiological implications and recommendations for physical and nutritional countermeasures. Eur J Sport Sci. 2021;21(4):614-635.

26. McCormick R, Vasilaki A. Age-related changes in skeletal muscle: changes to life-style as a therapy. Biogerontology. 2018;19 (6):519-536. doi:10.1007/s10522-018-9775-3

27. Gheno R, Cepparo JM, Rosca CE, Cotten A. Musculoskeletal disorders in the elderly. $J$ Clin Imaging Sci. 2012;2:39. doi:10.4103/2156-7514.99151

28. Vignoli M, Guglielmi D, Balducci C, Bonfiglioli R. Workplace bullying as a risk factor for musculoskeletal disorders: the mediating role of job-related psychological strain. Biomed Res Int. 2015;2015:712642. doi:10.1155/2015/712642

29. Lucchetti G, Oliveira AB, Mercante JP, Peres MF. Anxiety and fear-avoidance in musculoskeletal pain. Curr Pain Headache Rep. 2012;16(5):399-406. doi:10.1007/s11916-012-0286-7

30. Perez DL, Barsky AJ, Vago DR, Baslet G, Silbersweig DA. A neural circuit framework for somatosensory amplification in somatoform disorders. J Neuropsychiatry Clin Neurosci. 2015;27(1):e40-50. doi:10.1176/appi.neuropsych.13070170

31. Kershaw EE, Flier JS. Adipose tissue as an endocrine organ. J Clin Endocrinol Metab. 2004;89(6):2548-2556. doi:10.1210/ jc.2004-0395

32. Walsh TP, Arnold JB, Evans AM, Yaxley A, Damarell RA, Shanahan EM. The association between body fat and musculoskeletal pain: a systematic review and meta-analysis. $B M C$ Musculoskelet Disord. 2018;19(1):233. doi:10.1186/s12891-0182137-0

33. Altindag $\mathrm{O}$, Celik H. Total antioxidant capacity and the severity of the pain in patients with fibromyalgia. Redox Rep. 2006;11 (3):131-135. doi:10.1179/135100006X116628

34. Labianca R, Sarzi-Puttini P, Zuccaro SM, Cherubino P, Vellucci $\mathrm{R}$, Fornasari D. Adverse effects associated with non-opioid and opioid treatment in patients with chronic pain. Clin Drug Investig. 2012;32(1):53-63. doi:10.2165/11630080-000000000-00000

35. Wells N, Pasero C, McCaffery MC; Management ItQoCTPAa. Chapter 17. Improving the Quality of Care Through Pain Assessment and Management. Rockville (MD); 2008.

36. Ozbay F, Johnson DC, Dimoulas E, Morgan CA, Charney D, Southwick S. Social support and resilience to stress: from neurobiology to clinical practice. Psychiatry. 2007;4(5):35-40.

37. Petri RP Jr, Walter JA, Wright J. Integrative health and healing practices specifically for service members: self-care techniques. Med Acupunct. 2015;27(5):335-343. doi:10.1089/acu.2015.1121

38. Qaseem A, Wilt TJ, McLean RM, Forciea MA. Noninvasive treatments for acute, subacute, and chronic low back pain: a clinical practice guideline from the American college of physicians. Ann Intern Med. 2017;166(7):514-530. doi:10.7326/M162367
39. Steinhorn DM, Din J, Johnson A. Healing, spirituality and integrative medicine. Ann Palliat Med. 2017;6(3):237-247. doi:10.21037/apm.2017.05.01

40. Evans R, Vihstadt C, Westrom K, Baldwin L. Complementary and integrative healthcare in a long-term care facility: a pilot project. Glob Adv Health Med. 2015;4(1):18-27. doi:10.7453/ gahmj.2014.072

41. Dusek JA, Finch M, Plotnikoff G, Knutson L. The impact of integrative medicine on pain management in a tertiary care hospital. J Patient Saf. 2010;6(1):48-51. doi:10.1097/PTS.0b013e3 181d10ad5

42. Harris PE, Cooper KL, Relton C, Thomas KJ. Prevalence of complementary and alternative medicine (CAM) use by the general population: a systematic review and update. Int J Clin Pract. 2012;66(10):924-939. doi:10.1111/j.1742-1241.2012.02945.x

43. Grzywacz JG, Quandt SA, Neiberg R, Lang W, Bell RA, Arcury TA. Age-related differences in the conventional health care-complementary and alternative medicine link. Am J Health Behav. 2008;32(6):650-663. doi:10.5993/AJHB.32.6.9

44. Fjaer EL, Landet ER, McNamara CL, Eikemo TA. The use of complementary and alternative medicine (CAM) in Europe. BMC Complement Med Ther. 2020;20(1):108. doi:10.1186/s12906-02002903-w

45. Kemppainen LM, Kemppainen TT, Reippainen JA, Salmenniemi ST, Vuolanto PH. Use of complementary and alternative medicine in Europe: health-related and sociodemographic determinants. Scand J Public Health. 2018;46(4):448-455. doi:10.1177/1403494817733869

46. Leach MJ. Profiling the Australian consumer of complementary and alternative medicine: a secondary analysis of national health survey data. Altern Ther Health Med. 2016;22(4):64-72.

47. Sharp D, Lorenc A, Morris R, et al. Complementary medicine use, views, and experiences: a national survey in England. BJGP Open. 2018;2(4):bjgpopen18X101614. doi:10.3399/bjgpopen18X101614

48. de Moraes Mello Boccolini P, Siqueira Boccolini C. Prevalence of complementary and alternative medicine (CAM) use in Brazil. BMC Complement Med Ther. 2020;20(1):51. doi:10.1186/s12906020-2842-8

49. Cremaldi JC, Bhushan B. Bioinspired self-healing materials: lessons from nature. Beilstein J Nanotechnol. 2018;9:907-935. doi:10.3762/bjnano.9.85

50. Pimentel PP, Toldra RC. Self-healing method as strategy to promote health and rehabilitation of people with multiple sclerosis in the context of occupational therapy. Cad Bras Ter Ocup São Carlos. 2017;25(3):565-573. doi:10.4322/2526-8910.ctoAO0992

51. O'Donnell M. Health-promotion behaviors that promote selfhealing. J Altern Complement Med. 2004;10(Suppl 1):S49-60. doi:10.1089/acm.2004.10.S-49

52. Betts JG, Desaix P, Johnson E, et al. Anatomy and Physiology. Vol. 9. Houston, TX: OpenStax, Rice University; 2017.

53. Dusek JA, Benson H. Mind-body medicine: a model of the comparative clinical impact of the acute stress and relaxation responses. Minn Med. 2009;92(5):47-50.

54. Dusek JA, Chang BH, Zaki J, et al. Association between oxygen consumption and nitric oxide production during the relaxation response. Med Sci Mon Int Med J Exp Clin Res. 2006;12(1):Cr1-10.

55. Hallman DM, Lyskov E. Autonomic Regulation in Musculoskeletal Pain. IntechOpen; 2012.

56. Luberto CM, Hall DL, Park ER, Haramati A, Cotton S. A perspective on the similarities and differences between mindfulness and relaxation. Glob Adv Health Med. 2020;9:216495612 0905597. doi:10.1177/2164956120905597

57. Bau JG, Chia T, Wei SH, Li YH, Kuo FC. Correlations of neck/ shoulder perfusion characteristics and pain symptoms of the female office workers with sedentary lifestyle. PLoS One. 2017;12(1):e0169318. doi:10.1371/journal.pone.0169318 
58. Duda GN, Taylor WR, Winkler T, et al. Biomechanical, microvascular, and cellular factors promote muscle and bone regeneration. Exerc Sport Sci Rev. 2008;36(2):64-70. doi:10.1097/ JES.0b013e318168eb88

59. Fernando CA, Pangan AM, Cornelison D, Segal SS. Recovery of blood flow regulation in microvascular resistance networks during regeneration of mouse gluteus maximus muscle. $J$ Physiol. 2019;597(5):1401-1417. doi:10.1113/JP277247

60. Liu JT, Liao WJ, Chang CS, Chen YH. Lower limb pain caused by insufficient muscular microcirculation. Indian J Surg. 2014;76 (1):70-75. doi:10.1007/s12262-012-0628-z

61. Suzuki K. Chronic inflammation as an immunological abnormality and effectiveness of exercise. Biomolecules. 2019;9(6). doi:10.3390/biom 9060223

62. Behringer EJ, Segal SS. Spreading the signal for vasodilatation: implications for skeletal muscle blood flow control and the effects of ageing. $J$ Physiol. 2012;590(24):6277-6284. doi:10.1113/ jphysiol.2012.239673

63. Kuo IY, Ehrlich BE. Signaling in muscle contraction. Cold Spring Harb Perspect Biol. 2015;7(2):a006023. doi:10.1101/cshperspect. a006023

64. Darnall BD. Pain psychology and pain catastrophizing in the perioperative setting: a review of impacts, interventions, and unmet needs. Hand Clin. 2016;32(1):33-39. doi:10.1016/j.hcl.20 15.08 .005

65. Galambos A, Szabó E, Nagy Z, et al. A systematic review of structural and functional MRI studies on pain catastrophizing. $J$ Pain Res. 2019;12:1155-1178. doi:10.2147/JPR.S192246

66. Keijsers E, Feleus A, Miedema HS, Koes BW, Bierma-Zeinstra SM. Psychosocial factors predicted nonrecovery in both specific and nonspecific diagnoses at arm, neck, and shoulder. J Clin Epidemiol. 2010;63(12):1370-1379. doi:10.1016/j.jclinepi.2010.01.015

67. Linton SJ. A review of psychological risk factors in back and neck pain. Spine. 2000;25(9):1148-1156. doi:10.1097/00007632200005010-00017

68. Quartana PJ, Campbell CM, Edwards RR. Pain catastrophizing: a critical review. Expert Rev Neurother. 2009;9(5):745-758. doi:10. 1586/ern.09.34

69. Wang CK, Myunghae Hah J, Carroll I. Factors contributing to pain chronicity. Curr Pain Headache Rep. 2009;13(1):7-11. doi:10.1007/s11916-009-0003-3

70. Taber CB, Vigotsky A, Nuckols G, Haun CT. Exercise-induced myofibrillar hypertrophy is a contributory cause of gains in muscle strength. Sports Med. 2019;49(7):993-997. doi:10.1007/s40 279-019-01107-8

71. Lopes KG, Bottino DA, Farinatti P, et al. Strength training with blood flow restriction - a novel therapeutic approach for older adults with sarcopenia? A case report. Clin Interv Aging. 2019;14:1461-1469. doi:10.2147/CIA.S206522

72. Rolff S, Korallus C, Hanke AA. Rehabilitation mithilfe des „blood flow restriction training“. Der Unfallchirurg. 2020;123 (3):180-186. doi:10.1007/s00113-020-00770-1

73. Paolucci T, Zangrando F, Iosa M, et al. Improved interoceptive awareness in chronic low back pain: a comparison of back school versus Feldenkrais method. Disabil Rehabil. 2017;39(10):9941001. doi:10.1080/09638288.2016.1175035

74. Calner T, Isaksson G, Michaelson P. Physiotherapy treatment experiences of persons with persistent musculoskeletal pain: a Qualitative Study. Physiother Theory Pract. 2021;37(1):28-37.

75. Christenssen WD. Stretch exercises: reducing the musculoskeletal pain and discomfort in the arms and upper body of echocardiographers. J Diagn Med Sonogr. 2001;17(3):123-140. doi:10.1177/ 87564790122250318

76. Hug F, Tucker K. Muscle coordination and the development of musculoskeletal disorders. Exerc Sport Sci Rev. 2017;45(4):201208. doi:10.1249/JES.0000000000000122
77. Bialosky JE, Bishop MD, Price DD, Robinson ME, George SZ. The mechanisms of manual therapy in the treatment of musculoskeletal pain: a comprehensive model. Man Ther. 2009;14 (5):531-538. doi:10.1016/j.math.2008.09.001

78. Elma Ö, Yilmaz ST, Deliens $\mathrm{T}$, et al. Do nutritional factors interact with chronic musculoskeletal pain? a systematic review. $J$ Clin Med. 2020;9(3):702. doi:10.3390/jcm9030702

79. Song Z, Xie W, Strong JA, et al. High-fat diet exacerbates postoperative pain and inflammation in a sex-dependent manner. Pain. 2018;159(9):1731-1741. doi:10.1097/j.pain.0000000000001259

80. Mendonça CR, Noll M, Castro MCR, Silveira EA. Effects of nutritional interventions in the control of musculoskeletal pain: an integrative review. Nutrients. 2020;12(10):3075. doi:10.3390/nu12103075

81. Montenegro KR, Cruzat V, Carlessi R, Newsholme P. Mechanisms of vitamin D action in skeletal muscle. Nutr Res Rev. 2019;32(2):192-204. doi:10.1017/S0954422419000064

82. Dai Z, Koh WP. B-vitamins and bone health-a review of the current evidence. Nutrients. 2015;7(5):3322-3346. doi:10.3390/ nu7053322

83. Wang JH. Traditional Chinese medicine and the positive correlation with homeostatic evolution of human being: based on medical perspective. Chin J Integr Med. 2012;18(8):629-634. doi:10.1007/s11655-012-1170-3

84. Dong X, Li K. The association between musculoskeletal symptoms and traditional Chinese medicine use among Chinese older adults in the greater Chicago area. Gerontol Geriatr Med. 2018;4:2333721418778179.

85. Peng N, Yu M, Yang G, et al. Effects of the Chinese medicine Yi Shen Jian $\mathrm{Gu}$ granules on aromatase inhibitor-associated musculoskeletal symptoms: a randomized, controlled clinical trial. Breast. 2018;37:18-27. doi:10.1016/j.breast.2017.08.003

86. Silva H. Current knowledge on the vascular effects of menthol. Front Physiol. 2020;11:298. doi:10.3389/fphys.2020.00298

87. Sundstrup E, Jakobsen MD, Brandt M, et al. Acute effect of topical menthol on chronic pain in slaughterhouse workers with carpal tunnel syndrome: triple-blind, randomized placebo-controlled trial. Rehabil Res Pract. 2014;2014:310913. doi:10.1155/ 2014/310913

88. Brosseau L, Yonge KA, Robinson V, et al. Thermotherapy for treatment of osteoarthritis. Cochrane Database Syst Rev. 2003;2003(4):Cd004522.

89. Rennie GA, Michlovitz SL. Biophysical principles of heating and superficial heating agents. In: Michlovitz SL, editor. Thermal Agents in Rehabilitation. 3rd ed. Philadelphia, PA: FA Davis; 1996:107-167.

90. Nadler SF, Steiner DJ, Erasala GN, Hengehold DA, Abeln SB, Weingand KW. Continuous low-level heatwrap therapy for treating acute nonspecific low back pain. Arch Phys Med Rehabil. 2003;84(3):329-334. doi:10.1053/apmr.2003.50102

91. Freiwald J, Hoppe MW, Beermann W, Krajewski J, Baumgart C. Effects of supplemental heat therapy in multimodal treated chronic low back pain patients on strength and flexibility. Clin Biomech (Bristol, Avon). 2018;57:107-113. doi:10.1016/j. clinbiomech.2018.06.008

92. Stark J, Petrofsky J, Berk L, Bains G, Chen S, Doyle G. Continuous low-level heatwrap therapy relieves low back pain and reduces muscle stiffness. Phys Sportsmed. 2014;42(4):39-48. doi:10.3810/psm.2014.11.2090

93. Lai YT, Chan HL, Lin SH, et al. Far-infrared ray patches relieve pain and improve skin sensitivity in myofascial pain syndrome: a Double-Blind Randomized Controlled Study. Complement Ther Med. 2017;35:127-132. doi:10.1016/j.ctim.2017.10.007

94. Kirsch DL. Microcurrent electrical therapy (MET): a tutorial. PPM. 2006;6(7). Available from: https://www.practicalpainman agement.com/treatments/microcurrent-electrical-therapy-mettutorial. Accessed September 6, 2021. 
95. Vickers AJ, Vertosick EA, Lewith G, et al. Acupuncture for chronic pain: update of an individual patient data meta-analysis. $J$ Pain. 2018;19(5):455-474. doi:10.1016/j.jpain.2017.11.005

96. Lai HC, Lin YW, Hsieh CL. Acupuncture-analgesia-mediated alleviation of central sensitization. Evid Based Complement Alternat Med. 2019;2019:6173412. doi:10.1155/2019/6173412

97. Hussain J, Cohen M. Clinical effects of regular dry sauna bathing: a systematic review. Evid Based Complement Alternat Med. 2018;2018:1857413. doi:10.1155/2018/1857413

98. Pilch W, Pokora I, Szyguła Z, et al. Effect of a single Finnish sauna session on white blood cell profile and cortisol levels in athletes and non-athletes. J Hum Kinet. 2013;39(1):127-135. doi:10.2478/hukin-2013-0075

99. Tsai SR, Hamblin MR. Biological effects and medical applications of infrared radiation. $J$ Photochem Photobiol B 2017;170:197-207. doi:10.1016/j.jphotobiol.2017.04.014

100. Evangelidis M. Mindful yoga practices in the management of chronic musculoskeletal pain. Available from: https://www.acade mia.edu/35807634/Mindful_Yoga_Practices_in_the_ Management_of_Chronic_Musculoskeletal_Pain._Evidence_ based.Accessed December, 2020.

101. Hanley AW, Garland EL, Zingg RW. Mindfulness-based waiting room intervention for osteopathic manipulation patients: a pilot randomized controlled trial. J Osteopath Med. 2021;121(4):337348. doi:10.1515/jom-2020-0186

102. Polaski AM, Phelps AL, Smith TJ, et al. Integrated meditation and exercise therapy: a randomized controlled pilot of a combined nonpharmacological intervention focused on reducing disability and pain in patients with chronic low back pain. Pain Med. 2021;22(2):444-458. doi:10.1093/pm/pnaa403

103. Zeidan F, Vago DR. Mindfulness meditation-based pain relief: a mechanistic account. Ann N Y Acad Sci. 2016;1373(1):114-127. doi: 10.1111 /nyas. 13153

104. Marikar Bawa Fl, Sutton JW, Mercer SW, Bond CM. I'm empowered to look after myself - mindfulness as a way to manage chronic pain: an interpretative phenomenological analysis of participant experiences in Scotland. Soc Sci Med. 2021;281:114073. doi:10.1016/j.socscimed.2021.114073

105. Castro MM, Daltro C, Kraychete DC, Lopes J. The cognitive behavioral therapy causes an improvement in quality of life in patients with chronic musculoskeletal pain. Arq Neuropsiquiatr 2012;70(11):864-868. doi:10.1590/S0004-282X2012001100008

106. Ginandes C. Staying the course: using hypnosis to help cancer patients navigate their illness. Am J Clin Hypn. 2017;60(1):85102. doi:10.1080/00029157.2017.1316233

107. Saha TD, Kerridge BT, Goldstein RB, et al. Nonmedical prescription opioid use and DSM-5 nonmedical prescription opioid use disorder in the United States. J Clin Psychiatry. 2016;77(6):772780. doi: $10.4088 / \mathrm{JCP} .15 \mathrm{~m} 10386$

108. Verhamme KMC, Bohnen AM. Are we facing an opioid crisis in Europe? Lancet Public Health. 2019;4(10):e483-e484. doi:10. 1016/S2468-2667(19)30156-2

109. Babatunde OO, Jordan JL, Van der Windt DA, Hill JC, Foster NE, Protheroe J. Effective treatment options for musculoskeletal pain in primary care: a systematic overview of current evidence. PLoS One. 2017;12(6):e0178621. doi:10.1371/journal.pone.0178621

110. Barker I, Steventon A, Williamson R, Deeny SR. Self-management capability in patients with long-term conditions is associated with reduced healthcare utilisation across a whole health economy: cross-sectional analysis of electronic health records. BMJ Qual Saf. 2018;27(12):989-999. doi:10.1136/bmjqs-2017007635
111. Hoon E, Smith K, Black J, Burnet S, Hill C, Gill TK. Take charge of pain: evaluating a community-targeted self-management education program for people with musculoskeletal pain. Health Promot J Austr. 2017;28(1):77-80. doi:10.1071/HE15123

112. Kroenke K, Bair MJ, Damush TM, et al. Optimized antidepressant therapy and pain self-management in primary care patients with depression and musculoskeletal pain: a randomized controlled trial. JAMA. 2009;301(20):2099-2110. doi:10.1001/jama.2009.723

113. Walsh N, Jones L, Phillips S, et al. Facilitating activity and selfmanagement for people with arthritic knee, hip or lower back pain (FASA): a cluster randomised controlled trial. Musculoskelet Sci Pract. 2020;50:102271. doi:10.1016/j.msksp.2020.102271

114. Sørensen K, Van den Broucke S, Fullam J, et al. Health literacy and public health: a systematic review and integration of definitions and models. BMC Public Health. 2012;12(1):80. doi: $10.1186 / 1471-2458-12-80$

115. Jinnouchi H, Matsudaira K, Kitamura A, et al. Effects of brief self-exercise education on the management of chronic low back pain: a community-based, randomized, parallel-group pragmatic trial. Mod Rheumatol. 2021;31(4):890-898.

116. Rodríguez-Sánchez-Laulhé P, Luque-Romero LG, Blanquero J, et al. A mobile app using therapeutic exercise and education for self-management in patients with hand rheumatoid arthritis: a randomized controlled trial protocol. Trials. 2020;21(1):777. doi:10.1186/s13063-020-04713-4

117. Devan H, Hale L, Hempel D, Saipe B, Perry MA. What works and does not work in a self-management intervention for people with chronic pain? Qualitative systematic review and meta-synthesis. Phys Ther. 2018;98(5):381-397. doi:10.1093/ptj/pzy029

118. eTG.Therapeutic guidelines non-specific acute low back pain. Australia. Available from: https://tgldcdp.tg.org.au/searchAction? appendedinputbuttons $=$ therapeut $\% 20$ guidelin $\% 20$ nonspecif $\%$ 20acut\%20low\%20back\%20pain. Accessed December, 2020.

119. ACI NSW Agency for Clinical Innovation. Model of care. Management of people with acute low back pain; 2016. Available from: https://www.aci.health.nsw.gov.au/_data/assets/ pdf_file/0007/336688/acute-low-back-pain-moc.pdf. Accessed September, 2020.

120. Projeto Diretrize. Diagnóstico e Tratamento das Lombalgias e Lombociatalgias, Brazil; 2001. Available from: https://diretrizes. amb.org.br/_BibliotecaAntiga/lombalgias-e-lombociatalgias.pdf. Accessed September, 2020.

121. Associacao Brasileira de Medicina Fisica e R. Chronic nonspecific low back pain: rehabilitation. Rev Assoc Med Bras (1992). 2013;59(6):536-553.

122. Prise en charge du patient présentant une lombalgie commune. Recommandation de bonne pratique; 2019. Available from: https:// www.has-sante.fr/jcms/c_2961499/fr/prise-en-charge-du-patientpresentant-une-lombalgie-commune. Accessed September, 2020.

123. Société Française de Rhumatologie. How is low back pain or common low back pain treated? (Comment se traite une lombalgie ou une lomboradiculalgie commune?); 2019. Available from: https://public.larhumatologie.fr/grandes-maladies/mal-de-dos-lom balgie/comment-se-traite-une-lombalgie-ou-une-lomboradiculal gie. Accessed September, 2020.

124. Chenot JF, Greitemann B, Kladny B, Petzke F, Pfingsten M, Schorr SG. Non-specific low back pain. Dtsch Arztebl Int. 2017;114(51-52):883-890.

125. AWMF (Association of the Scientific Medical Societies in Germany). S2k LL specific LBP; 2018. Available from: https:// www.awmf.org/uploads/tx_szleitlinien/033-051 m_S2k_ Spezifischer_Kreuzschmerz_2018-02.pdf. Accessed September, 2020. German. 
126. NICE. Guideline (NG59): 'low back pain and sciatica in over 16's: assessment and management'; 2016. Available from: https://www. nice.org.uk/guidance/ng59. Accessed September, 2020.

127. Agency for Healthcare Research and Quality. Effective healthcare program. Noninvasive treatments for low back pain; 2016. Available from: https://effectivehealthcare.ahrq.gov/products/ back-pain-treatment/clinician. Accessed September, 2020.
128. Pangarkar SS, Kang DG, Sandbrink F, et al. VA/DoD Clinical Practice Guideline: Diagnosis and Treatment of Low Back Pain. J Gen Intern Med. 2019;34:2620-2629. doi:10.1007/s11606-019-05086-4

\section{Publish your work in this journal}

The Journal of Pain Research is an international, peer reviewed, open access, online journal that welcomes laboratory and clinical findings in the fields of pain research and the prevention and management of pain. Original research, reviews, symposium reports, hypothesis formation and commentaries are all considered for publication. The manuscript management system is completely online and includes a very quick and fair peer-review system, which is all easy to use. Visit http:// www.dovepress.com/testimonials.php to read real quotes from published authors. 